\title{
Consciousness in medical practice
}

Mircea Gelu Buta

Babes-Bolyai University of ClujNapoca, Romania
DOI: $10.15386 / \mathrm{mpr}-2435$

Manuscript received: 18.11.2021

Accepted: 08.12.2021

Address for correspondence:

butamircea@yahoo.com

This work is licensed under a Creative Commons Attribution-NonCommercialNoDerivatives 4.0 International License

\begin{abstract}
When Professor Iuliu Haţieganu linked the field of medical science to consciousness, I think he was referring to human power, meaning the inner feeling through which one realizes the good or evil he can do. It is what we also call moral virtues, which have politeness as a starting point and love as a terminus. If virtue can be learned - and I believe it can be, it happens more through the power of example than from books. The humanistic tradition of the school he leads and the professional development of his students depend on the ethical qualities of the teacher. Science brings innovations, the school led by true masters receives them and makes them fruitful.
\end{abstract}

Keywords: consciousness, virtues, medicine

\section{Introduction}

The traditional physician, as we know him since ancient times, was defined morally by calm, devotion, and modesty. But it is a discretionary attitude, essentially dominated by "good intentions", dependent on Rabelais' Enlightenment perception: "Science without consciousness is the ruin of the soul." Regarding medicine, the exact report was formulated by Iuliu Hațieganu through the well-known phrase: "Medicine is science and conscience", the motto of Cluj medical school.

Looking at things objectively, even from the perspective of faith, we must recognize that in recent decades medicine has made astonishing progress. Medicine, as a branch of science, following the course of contemporary society, which with a generic term is called saeculum or the spirit of the times, has begun to forget or neglect its fundamental mission, that of preventing and caring for diseases and disabilities. Medicine has sought to become increasingly involved both in improving the quality and comfort of life and in changing the physical and intellectual performance of the human body. In the pursuit of performance, the doctor as a scientist, seduced by technology, attempted to explore the new possibilities offered by it and began to gradually move away from both the biopsycho-social component of man and his existential problems [1].

More and more non-medical specialists (engineers, physicists, chemists, biologists, mathematicians, etc.) are involved in the medical activity, communicating with the patient through devices. Nor can the doctor disregard the technical facilities, which he needs, in addition to medical science; paramedical knowledge, a certain technicality, the use of an increasingly sophisticated device that requires specific training have become an intrinsic part of the profession.

All these phenomena whose necessity is unanimously accepted sometimes represent reasons for justified concern, provoke discussions and controversies, determine positions and concerns in order to remedy attitudes and gestures that can be interpreted as dehumanizing for the medical act. 
Partisans of "classical" or "modern" medicine appear, nostalgia is expressed for "la belle époque" of clinical medicine, invitations are launched for "retreat under the Hippocratic plane trees from Cos"

Are all these worries, such nostalgia, justified in a world full of progress in which the rhythm of modern life and the dizzying transformations around us limit the time we have to rest under the plane trees of Cos?

\section{About the virtues of the doctor}

When Professor Iuliu Hațieganu linked the field of medical science to consciousness, I think he was referring to human power, meaning the inner feeling through which one realizes the good or evil he can do. It is what we also call moral virtues, those that make a man care, as Montaigne said [2], be more human or better than another and without which, says Spinoza [3], we would rightly be considered inhuman.

Medical morality begins with spiritual politeness. I say this because good manners precede good deeds and command them [4]. So politeness is a value, which cannot be disputed. However, it is an ambiguous value, being able to mask the best but also the worst intentions, which is why it sometimes seems suspicious. Politeness should be in people's nature. Of course, there is a false politeness, which hides cynicism in deeds. Good manners are aggravating circumstances in this case. For example, the Nazis played Beethoven while killing children in concentration camps.

I said morality begins trough politeness and continues, changing its nature, through honesty. In other words, the doctor only has to do what he knows how to do well. If he is convinced that a confrere has more experience in a certain field, he has to have the strength to send the patient to him. Before pride, material or other considerations, there must be an interest in the patient. Knowing how to ask for or receive advice is a great thing. Erasmus, the great humanist, said that no gift is more precious than the good advice. Hence the rule of asking for advice someone with more experience, when you are at a standstill.

Responsibility requires the doctor to motivate his gestures not only by the intentions and principles he has, but also by the consequences of his actions to the extent he can foresee. In fact, prudence is an "intellectual virtue", as Aristotle warns us " $a$ virtue that belongs to the truth, knowledge, reason". Prudence is the quality that allows us to correctly interpret what is good or bad for the patient and to act accordingly [5]. In his book "On Epidemics", Hippocrates writes, "In the fight against disease, two things are required: to help or not to do harm." In the following centuries, the record was amputated, keeping only the final restriction: "Primum non nocere". With this invitation to caution, however, many errors were caused, as the fear of not aggravating the patient's condition has led to a passive attitude of non- engagement, obviously much more comfortable for the doctor.

Contemporary medicine has been forced to reanalyze the Hippocratean incentive "Primum non nocere" in a more engaging spirit, so it has become: "Primum utiliz esse et nil nocere." It is a matter of doing something for the patient, however, without aggravating his suffering. But for that you need courage. Of all the virtues, courage is undoubtedly admired in the most unanimous way. However, this unanimity does not prove anything, it even appears suspicious. Unanimously admired means admired by both the good and the bad but also by idiots. What confidence can we have in their judgment? After all, virtue is not a spectacle, and applause is of no use to them. The courage shown by a doctor during his interventions can only become a virtue when he is put in the service of a generous cause. As a character trait, courage is first and foremost a lack of sensitivity to fear, a lift above it through an effort of will and generosity. Courage is useless if it has no measure. Aristotle said that. The risks must be proportionate to the intended purpose. Temperance helps the doctor not exceed his limits. Temperance is that moderation by which we remain masters of our knowledge and gestures. With the help of temperance we do not exceed our possibilities, but we learn to respect them. It is an embodiment of what Foucault calls self-care and care for the other [6].

Imposing medical guidelines and protocols perceived by their technical nature as an ordering and professionalization of medical thinking is ultimately only a way of legal protection of the doctor in front of an autonomous and aggressive society. Of course, medicine is a complex science that has evolved from craft to art and then to science. Undoubtedly, it is a bold profession that involves permanent changes in the knowledge of variable information, practiced by people, who can also be subject to error. In addition, there is a high degree of risk, because the gap between what we know and what we want to do still exists and complicates all our actions.

I have often wondered what a "right doctor" means. Is it a person who respects the law? I don't think so, because laws can be unfair. The one who obeys the moral law? I met many confreres who did not claim to know it, some even denying its existence. However, there is a need for a criterion and a principle, no matter how uncertain, that should take into account equality or reciprocity between people. Here is the origin of the word equity (aequus), synonymous with justice. To take advantage of the naivete of a child, the ignorance of an ignorant, the unconsciousness of a madman, the despair of one who has reached the end of his powers, to obtain from them in ignorance something that contradicts their interests and intentions means to be unjust [6]. Gentleness and compassion do not take the place of justice, at most they 
can mark the beginning. That is why justice is important first and foremost for the weak, when we see how the economic condition strongly affects the medical act. Due to financial constraints we face situations in which, theoretically, we know more than we can practically do. On the other hand, we are witnessing a brutal economic polarization of society. The rich are getting richer, and the poor are getting poorer. Under these conditions, the chances of access to health services cannot be equal at all, they are different for the privileged and disadvantaged. How much attention do you pay to the street tramp when we learn that Russian physicist Lev Davidovich Landow, a member of the Academy, received the Nobel Prize after being taken out of a deep post-traumatic coma that lasted more than 40 days? Or is it known that artificial maintenance in life would have been interrupted under normal conditions, after 24-48 hours from the moment of disappearance of brain activity? The fact that 'statist' healthcare is at the opposite pole, dependent on the health insurance budget, shows that the main parameter that stands out in the healthcare economy is that of profitability, in the sense of amortizing investments, and especially maximizing benefit [7].

The fact that today we are overusing the word 'solidarity' proves our prudence in expression, as lexicographers point out, and the word has become in the socio-political vocabulary a prudent substitute for equality, justice and generosity [8]. However, these virtues belong to different registers. Hence the feeling that justice is more important, urgent and necessary, while generosity would be a luxury, an addition to the soul. Referring to this subject Descartes, explains in Article 156: "Those who are generous have a natural inclination to do great things, and at the same time to undertake only the deeds of which they are capable of. And, as nothing seems greater to them than to do good to others, despising their own interests, they are kind and ready to help anyone. This makes them fully master their own passions, especially desires, jealousy and envy." [9].

Like other virtues, generosity is multiple in content, hence the multitude of terms. Accompanying courage, generosity can mean heroism. Associated with justice, it becomes equity. When it joins compassion it turns to benevolence. However, its secret is when it meets gentleness and we call it kindness [6].

We return with gratitude to those masters, generous by nature, who wanted to modestly share with all disciples, students or young doctors, participants in courses or visitors to the sick patient wards, their knowledge of scholars and practitioners, understanding that a teacher lives not only through himself, but also through the disciples he had, thus reminding us of the words of Pliny the Younger in Trajan's panegyric: "Certissima divinitatis fides sunt boni successores" [10].

\section{Recognition of medical error}

In medicine, the truth has found its place among hypotheses and even errors. It was the tribute that medical progress had to pay over time. Specialists tell us that if a driver makes an error every $3 \mathrm{~km}$, the practitioner makes at least one error a day, technical progress multiplying the risks of errors and confirming that in medicine, without accepting risks, there can be no therapeutic success and no medical progress.

The need to acknowledge medical mistakes in order to prevent others from committing them has always been recognized. Hippocrates and Celsus have supported it since antiquity, and then many others. Referring to this problem, the great surgeon Nikolay Pirogov said that a doctor on whom the patient's destiny depends and a teacher who teaches his students has, compared to the tasks that often exceed him, a single right attitude, to tell nothing but the truth. In this respect, the diagnosis is a matter of conscience [11].

Ethically, not acknowledging or hiding the mistake becomes more reprehensible than the mistake itself. It was said by J.L. Petit 200 years ago: "Mistakes are only mistakes when you have the courage to publish them, but they become crimes when pride causes you to hide them" [12].

If the doctor must be ruthless about his own mistakes, he must show some indulgence towards the mistakes of others. "Forgive others often never yourself", said Publilius Syrus [13].

Aristotle speaks of unpredictable misfortunes, of mistakes and insults, in the desire to reveal the heuristic value of error and mistake. Therefore, the knowledge and recognition of medical errors, following the anatomicalclinical analyses made by professionals, it is a useful and ethical way to eliminate them in the future.

Diagnostic errors must be discussed in large groups, within the same specialty or in different specialties, so that the lessons can be learned by as many people as possible. From this point of view, the anatomical-clinical sessions become extremely instructive, because they try to understand the pathophysiological mechanisms that intervened in the evolution of the diseases and unfortunately led to death. We participated in such meetings during student life in Iasi, when in the last week of each month, usually on Wednesday evening, we hurried to take a seat in the lecture hall of "Forensic Medicine" to attend an anatomical-clinical duet, in which physicians in various specialties held their own views on the evolution of some clinical cases, and the scientific debate did not cease until the parties agreed on a common point of view. I met the same working spirit again in Cluj, where all the specialists from the Pediatric Clinics participated, together with the anatomo-pathologist, the late professor Petre Florescu, who also had the role of referee. It was a remarkable thing to see all those young and old people, 
eager for progress, who, renouncing pride and their own false humor, examined failures in an atmosphere of sincerity, without misinterpreting the statements of the anatomo-pathologist with the only desire to learn all the lessons.

I remember the case of a child born at a fullterm, by cesarean section, from pregnancy 2G2P, with W $3200 \mathrm{~g}$, having the following diagnosis.: right forearm malformation, lower limbs with absent calves; which parents asked for an investigation, accusing the doctors of malpractice.

Parents' statement: "Both in the private office of the doctor who supervised the pregnancy and in the private clinic where the pregnant mother was consulted, the doctors told the future mother that she would have a healthy child ... At the ultrasounds performed, we were shown what would have been the child's fingernail. Then, after the birth, we were told that in my wife's placenta some strands were created, which wrapped around the legs and the right hand and ended by strangling the limbs, leading to their detachment. Other doctors I spoke to said that the baby had a genetic malformation and has never had these limbs "...

The question that arose was whether the disability could be detected in the first 12 weeks of pregnancy, thus depriving the woman of the right to resort to therapeutic termination of pregnancy. Because medical courts refuse to list these diseases, and couples request abortions in the case of minor malformations such as: rabbit lip, absence of fingers, etc., jurisprudence should try to make judges assess these situations in the knowledge of Cause. The dispute of the birth of a child with disabilities risks generating another, namely the assessment of the conditions for termination of pregnancy for therapeutic reasons. However, we can fear that this jurisprudence stigmatizes children born with disabilities, serious and incurable diseases, and parents will have the exclusive right to decide the child's birth. The suggestion that the birth of a child with disabilities can be harmful is a dangerous message for society, because tradition starts from the principle that a newborn, whether healthy or not, has the right to live, to be cared for, to be accepted and respected by all [14].

The mere fact of making a misdiagnosis or choosing a certain therapeutic method is not enough to engage medical responsibility. Only mistakes that a good doctor, placed in the same circumstances, would not have made are attributable. The doctor has no obligation of the result, but has the obligation to choose the means, which is to justify his choices and acts, depending on what is considered to be good practice of the moment.

Failure to comply with professional practices that have become classic, meaning established and commonly accepted rules that make up the good practice of the moment, can lead to imputable errors: incomplete or superficial examination of the patient; lack of preoperative examination; non-compliance

Without a detailed analysis of misfortunes, incidents, near misses, and "free lessons," we have no way of discovering the pitfalls of recurring errors or knowing where the "edge" is until we collapse. For example, the complete absence of such reporting culture crucially contributed to the Chernobyl disaster, where operators misinterpreted standard plant protection procedures and shut down successive safety systems, creating the immediate trigger for the catastrophic explosion in the core [15].

Sincerity and fairness are key elements of a culture of analyzing errors and mistakes in the medical system. First of all, reality has shown that there are situations in which the best professionals have made the worst mistakes, in other words the error is not the monopoly of a few unhappy people. Second, far from being random, they often fall into recurring patterns, meaning that the same set of circumstances can cause similar errors, regardless of the people involved.

Mistakes are inevitable, and if you try to eliminate all the doctors who make mistakes, there will be almost none left. This is the lesson of the mistake of diagnosis and treatment, a lesson of modesty, of the desire to learn, to make progress, to obtain better results. The doctor must put everything, even the mistake, in the service of healing the suffering man.

\section{Objections triggered by "conscience" in medicine}

There are voices insisting that doctors should not validate their own ethical views in practice by refusing to provide medical care as required by law [16]. Accused of the "incompatibility thesis", they refer to "refusals based on the conscience to provide goods and services legally and professionally authorized within the competence of a practitioner, but which are incompatible with the practitioner's professional obligations" [17]. These are contraceptive abortions, medically assisted euthanasia, the execution of prisoners, the facilitation of torture for interrogations, the harvesting of organs from the donor, the withdrawal of nutrition and hydration, the treatment of sexually active gay patients, sex change, etc. Hence the concern that patients requesting such services may depend on the whims of the conscience of some doctors, while their colleagues will be unjustly burdened with additional work by their random refusals.

The extraordinary progress of medical knowledge has necessitated the reformulation of many ethical attitudes regarding the prevention and treatment of diseases. Numerous surveys conducted among physicians regarding their views on sensitive issues of medical practice such as euthanasia, abortion, etc., have highlighted a wide variety of responses with a certain dynamic over time. 
The conclusions of the studies were related to tolerance, negotiation and compromise, concrete practical judgments and less abstract ethical theories [18].

Physicians and pharmacists who conscientiously refuse to participate in certain legally standardized practices are accused of introducing personal views into medical practice in an unprofessional manner. On the other hand, given the pathocentric nature of medicine, the refusal to induce a pathology following an abortion, contraceptive maneuvers, euthanasia, etc., is in fact an attitude loyal to the internal morality of medicine. The refusal of a doctor to participate in an execution is not wrong because it comes in direct conflict with the essence of the medical practice to which doctors engage. Likewise, abortion can fall into the same category, because it has as its ultimate goal the end of life.

Mainly, a distinction needs to be made between 'conscientious objection' and refusals on religious, idiosyncratic or fanatical grounds [19]. For example, a Muslim woman who does not want to see naked male patients cannot appeal to the pathocentric nature of medicine and the internal morality of the profession. So do Muslim medical students who refuse to learn about sexually transmitted and alcohol-related illnesses because they would be offended by their religious sensibilities [20]. The same is true for a Jewish doctor who does not want to offer medicines made with non-kosher gelatine or a surgeon who is a Jehovah's Witness who will not use blood transfusions. These practices, which have nothing to do with the principles of medicine, can destroy patients' expectations, worsen their health and overwhelm the work of colleagues, who are forced to take on the responsibilities of others unjustly [21].

What interests us is the situation in which the refusal is based on the values of the doctor as a professional, not as a Christian or any other religion. To analyze this, let us consider the case of abortion again. We might imagine that a Christian physician refuses to perform this procedure by appealing to the values enshrined in Scripture or in the official teaching of the Church. Such a refusal would be based on the Christian beliefs of the doctor. There is therefore a fear that this would allow a doctor to refuse from religious beliefs procedures commonly accepted and practiced by professionals. However, conscientious objections would be legitimate only if they involve procedures that induce pathologies. In other words, a doctor's refusal to perform an abortion can be justified on the basis of values related to the essence of medicine, that is to prevent and treat diseases. This significantly limits the number of procedures that doctors would be allowed to refuse.

Many wonder if Christianity makes a difference in the doctor-patient relationship, at least in terms of the issue of conscientious objection. Some authors deny this by stating that Christian physicians often have objections to abortion and medically assisted suicide, and their refusal to perform such practices should be respected, because they are essentially based on the internal morality of medicine, which in turn it is based on a pathocentric model of medical practice [22].

\section{Conclusions}

1. The moral phenomenology of the doctor's conscience begins with politeness and ends with love. Between the two virtues so unequal in moral value, but so necessary, are placed in order: fidelity, prudence, temperance, courage, justice, generosity, compassion, gratitude, gentleness, good faith, and a sense of humor.

2. In principle, a distinction needs to be made between "conscientious objection" which is legitimate only when it involves procedures that induce pathologies and refusals on religious, idiosyncratic or fanatical grounds.

3. In connection with the severity of the mistake in diagnosis we distinguish three degrees: inaccuracy of diagnosis, when it comes to a simple formulation defect; the diagnostic mistake, when there is a partial mismatch; and the diagnostic error, when the mismatch is total. In everyday speech, a distinction is rarely made between diagnosis mistake and diagnosis error.

4. Medicine is not only a succession of successes, it is also sprinkled with bitter disappointments. This teaches the doctor to be modest, and the way to recovery is a safe one. To resume diagnosing and prescribing treatments. Only then will he forget the pains he went through.

\section{References}

1. Buta MG, Buta IA. Bioetica între mărturisire și secularizare [Bioethics between confession and secular]. Ed. Renaşterea, Cluj-Napoca, 2008; p. 142 [Romanian]

2. Montaigne. Eseuri [Essays]. II, 36, Ed. Minerva, București, 1984 [Romanian]

3. Spinoza. Etica [Ethics]. IV Ed. Științifică și Enciclopedică, București, 1981 [Romanian]

4. Kant. Critica rațiunii pure [Critique of Pure Reason]. Ed. Ştiinţifică, București, 1969 [Romanian]

5. Aristotel. Etica Nicomahică [Nicomachean Ethics]. VI. 5, 1140, a-b [Romanian]

6. André Comte-Sponville. Mic tratat al marilor virtuți [Small Treatise of Big Virtues]. Ed. Univers, București, 1998; p. 47 [Romanian]

7. Buta MG, Bioetică și slujire creștină [Bioethics and Christian Service]. Ed. Renașterea, Cluj-Napoca, 2017; p. 73-76 [Romanian]

8. Dictionnaire historique de la langue française. Dictionnaires Le Robert 1992, entry Solidarite [French]

9. René Descartes. Pasiunile sufletului [Passions of the soul]. Ed. Științifică și Enciclopedică, București, 1984; p. 153, 156, 187 [Romanian] 
10. Protase D. Împăratul Traian în viziunea lui Plinius cel Tanar și Caussius Dio [Emperor Trajan in the paperworks of Plinius Second and Cassius Dio]. BHAUT - Bibliotheca Historica et Archaeologica Universitatis Timisiensis 2006;7:136 [Romanian]

11. Brînzeu P. Curs liber de cultură medicală generală - Arta diagnosticului şi simţul clinic [Free course of general medical culture - the art of diagnosis and clinical sense]. Ed. Victor Babeș Timișoara, 2020; p. 178 [Romanian]

12. The Reverend JL Petit and the Beauty of Churches. British Art Journal. 2017;18:2.

13. Rus V. Un destin singular: Publilius Syrus și maximele sale [A strange destiny: Publilius Syrus and his maxims]. Tribuna (Cluj-Napoca). 2003;12:9-10.

14. Nisand I, Araújo-Attali L, Schillinger-Decker A-L, L'IVG, Que sais-je? Presses Universitaires de France, 2012.

15. Reason J. Human error: models and management. BMJ, 2000;320:768-770.

16. Savulescu J. Conscientious objection in medicine. BMJ. 2006;332:294-297.
17. Wicclair M. Conscientious Health Objection in Health Care. Cambridge, United Kingdom: Cambridge University Press, 2011.

18. Dumitrașcu D. Medicina între miracol și dezamăgire [Medicine between miracle and disappointment]. Ed. Medicală Universitară Iuliu Hațieganu, Cluj-Napoca, 2009; p. 58 [Romanian]

19. Hershenov DB. Pathocentric health care and a minimal internal morality of medicine. J Med Philos. 2020;45:1627.

20. Foggo D, Taher A. Muslim medical students get picky. The Times [Online] 2017. Available from: https://www. thetimes.co.uk/article/muslim-medical-students-get-picky20j9vjz65tg

21. Savulescu J, Schuklenk U. Doctors have no right to refuse medical assistance in dying. Abortion or Contraception. Bioethics. 2017;31:162-170.

22. Hershenov D. Conscientious objection or an internal morality of medicine? Christian Bioethics. 2021;27:104121. 